\title{
Eficacia de una dosis única de vacuna oral inactivada contra el cólera en Bangladesh
}

Efficacy of a single-dose, inactivated oral cholera vaccines in Bangladesh

Quadri F y col. N Engl J Med. 2016; 174(18):1723-32.

\section{Objetivos}

Determinar la eficacia de una dosis única de vacuna inactivada de bacterias muertas contra el cólera (usualmente administrada en dos dosis cepa 0139), en un área urbana con alta endemicidad de Vibrio cholerae.

\section{Diseño, lugar y pacientes}

Ensayo aleatorizado individual para medir eficacia de una vacuna. Realizado en barrios carenciados de una zona urbana de la ciudad de Dhaka, Bangladesh. Participaron en el estudio 204.700 personas no embarazadas de al menos 1 año de edad.

\section{Intervención}

Administración oral de una sola dosis de vacuna anticólera $\left(\right.$ Shanchol $\left.{ }^{\circledR}\right)$ o placebo. Vacuna y placebo tenían la misma apariencia y volumen $(1,5 \mathrm{ml})$. La detección de los casos de diarrea tratadas en los hospitales y centros de salud donde concurría la población de los barrios incluidos en el estudio, fue realizada durante el periodo comprendido entre los 7 y los 180 días posteriores a la aplicación de la vacuna o el placebo. Los pacientes con diarrea fueron identificados mediante el uso de una tarjeta identificatoria asignada a cada participante del estudio y su grupo familiar o por búsqueda electrónica computarizada en los registros del centro de tratamiento.

\section{Medición de resultado primario y secundario}

El resultado primario del ensayo de eficacia de la vacuna fue un episodio de cólera, definido como un episodio de diarrea no sanguinolenta con inicio en al menos 7 días posteriores al día de la administración de la vacuna o placebo, con aislamiento en materia fecal del paciente de V. cholerae $\mathrm{O} 1$ o $\mathrm{O} 139$ y confirmación de la identidad del paciente tratado por diarrea mediante visita a su domicilio posterior al alta médica. El resultado secundario fue un episodio de cólera severa, definido como un episodio de cólera con aislamiento de V. cholerae $\mathrm{O} 1$ o 0139 en materia fecal del paciente y severa deshidratación de acuerdo con los criterios de la Organización Mundial de la Salud (OMS). ${ }^{1}$

\section{Resultados}

Un total de 101 episodios de cólera, 37 asociados a deshidratación severa, fueron detectados entre las 204.700 participantes. La eficacia protectora de la vacuna contra el cólera se describe en la Tabla 1. La eficacia protectora de la vacuna contra todos los casos de cólera en personas de entre 5 y 14 años, mayores de 15 años y entre 1 y 4 años de edad fue de $63 \%$ (IC95\% $-39 \%$ a $90 \%), 56 \%$ (16\% a $77 \%$ ) y $16 \%$ (-49\% a $53 \%)$, respectivamente. No hubo diferencias significativas entre los diferentes grupos etarios $(p=0,25)$. Los eventos adversos ocurrieron con frecuencias similares en ambos grupos.

Tabla 1. Incidencia de eventos en ambos grupos y eficacia protectora de una dosis de vacuna anticolérica.

\begin{tabular}{l|c|c|c}
\hline Evento & $\begin{array}{c}\text { Vacuna } \\
\text { Casos/100000 personas-dia (IC 95\%) }\end{array}$ & $\begin{array}{c}\text { Placebo } \\
\text { Casos/100000 personas-dia (IC 95\%) }\end{array}$ & Protección (IC95\%) \\
\hline Cólera & $0,25(0,18 \mathrm{a} 0,34)$ & $0,41(0,32 \mathrm{a} 0,53)$ & $40 \%(11 \mathrm{a} 60 \%)$ \\
\hline Cólera severo & $0,06(0,02 \mathrm{a} 0,12)$ & $0,18(0,12 \mathrm{a} 0,26)$ & $63 \%(24 \mathrm{a} 82 \%)$ \\
\hline
\end{tabular}

\section{Conclusiones}

Una dosis única de la vacuna oral contra cólera fue eficaz en niños mayores de 5 años y en adultos pertenecientes a una comunidad con alta endemicidad de cólera.
Fuente de financiamiento: Beca de la Fundación Bill and Melinda Gates/ International Vaccine Institute/ Gobiernos de Australia, Bangladesh, Canadá, Suecia y Reino Unido.

\section{Comentario}

El principal hallazgo de este ensayo es que una sola dosis de la vacuna provee una aceptable protección contra el cólera por un periodo de al menos 6 meses a niños mayores de 5 años y adultos. Esta protección puede tener un impacto apreciable en comunidades, como la descripta en el artículo, en las que el cólera es endémico y existen problemas de infraestructura que impiden la aplicación de las 2 dosis de la vacuna. El estudio tiene tres limitaciones. En primer lugar, fue llevado a cabo en una región en la que el cólera es endémico, por lo tanto, su población tiene cierta inmunidad natural contra el V. cholerae y en consecuencia, los hallazgos no pueden generalizarse a poblaciones que carezcan de esa inmunidad natural. En segundo lugar, debido al diseño aleatorizado individual del estudio, no fue posible determinar el efecto rebaño inducido por la vacuna. Por último, la eficacia pro- tectora de la vacuna fue medida por un periodo de solo 6 meses posterior a la inmunización.

\section{Conclusiones del comentador}

El cólera no es endémico en la Argentina, por lo que la aplicación de una vacuna como medida preventiva no sería necesaria. La mayoría de las personas que viajan a lugares donde el cólera es endémico o epidémico tienen bajas chances de infectarse con $\mathrm{V}$. cholerae si siguen las normas de higiene para evitar enfermedades infecciosas trasmitidas por alimentos o agua. ${ }^{2,3}$ Sin embargo es recomendable la aplicación de una vacuna anticólera a personas que viajan para trabajar en campos de refugiados o barrios precarios en países con cólera endémico o epidémico.

Jerónimo Cello [Center for Infectious Diseases, Department of Molecular Genetics and Microbiology, School of Medicine, Stony Brook University, USA, jeronimo.cello@stonybrook.edu ]

Cello J. Eficacia de una dosis única de vacuna oral inactivada contra el cólera en Bangladesh. Evid Act Pract Ambul. 2017;20(1):10. Comentado de: Quadri F y col. Efficacy of a single-dose, inactivated oral cholera vaccines in Bangladesh. N Engl J Med. 2016;174(18):1723-32. PMID: 27144848.

Referencias

1. World Health Organization (WHO). The treatment of diarrhoea: a manual for physicians and other senior health workers. http://apps.who.int/iris/bitstream/10665/43209/1/9241593180.pdf

2. Swerdlow DL, Ries AA. Cholera in the Americas. Guidelines for the clinician. JAMA 1992; 267:1495

3. Craun G. y col. Prevention of water-borne cholera in the United States. J AM Waterworks Assoc 1991; 83: 40. 